\title{
Stances, Voluntarism, Relativism
}

\author{
Martin Kusch
}

\section{$\S 1$. Introduction}

In this paper I want to explore two ideas put forward and defended in Bas van Fraassen's The Empirical Stance (2002) (=ES) as well as in some related papers. The first idea is that many philosophical positions are best rendered not as "doctrines" but as "stances," that is, as sets, systems or bundles of values, emotions, policies, preferences, and beliefs. (To avoid torturous repetition, I shall refer to sets of values, emotions, policies and preferences as "VEPPs".) The second idea is a form of epistemology that van Fraassen calls "epistemic voluntarism." It is based on the rejection of two received views: that principles of rationality determine which philosophical positions and scientific paradigms we must adopt, and that epistemology is (akin to) a descriptive-explanatory (scientific) theory of cognition. I shall relate the stance-idea and epistemic voluntarism to debates over (epistemic) relativism.

\section{§2. Stances}

ES seeks to renew empiricism. According to van Fraassen, empiricism is first and foremost a "rebellion" against metaphysics. This is because "metaphysicians interpret what we initially understand into something hardly anyone understands, and then insist that we cannot do without that" (2002: 3). Take the question "Does the world exist?" To answer this question, metaphysicians use a technical concept of world. David Lewis for instance holds that a world simply is "the sum of all things spatio-temporally related to a given thing" (2002: 10). How does Lewis arrive at this result? Why is the mingle-mangle of things more or less distantly related to me "a world?" As ES sees it, Lewis simply "postulates" how "world" is to be understood and that it exists. It is here that van Fraassen "rebels:" “... I did not ask whether the 
existence of the world can be consistently postulated! I asked: Does the world exist?“ (2002: 10).

Empiricism rejects Lewis' and other metaphysicians' theorizing. This rejection is motivated by empiricism's core elements. In order to explain what these core elements are, van Fraassen first offers a reflection on how in general philosophical positions are to be understood. His primary target is what he calls "Principle Zero:"

(Principle Zero) For each philosophical position $X$ there exists a statement $X_{+}$ such that to have (or take) position $X$ is to believe (or decide to believe) that $X+$. (2002: 41)

Assume Principle Zero were adequate. What then would be the dogma " $E+$ " for empiricism? Going by the received (textbook) view, the most obvious candidate, at least for the "naïve empiricist," is the following:

$(E+)$ Experience is the one and only source of information. (2002: 43)

If Principle Zero were correct, van Fraassen thinks, then it would have to be able to perform a crucial critical function. For any alternative $(=A)$ to empiricism, if $A^{\prime} s A+$ were to turn out incompatible with $E+$, then the (naïve) empiricist would thereby have reason enough to reject $A$, and even without entering into any further argumentative give-and-take. For instance, given Principle Zero, an empiricist critique of metaphysics would have to show no more than that metaphysics and its central dogma is incompatible with $E+$.

ES does not accept Principle Zero and its interpretation of the encounter between empiricism and metaphysics. In order to summarize the argument succinctly, I shall use "empiricism $E_{+}$" for an empiricism rendered in terms of Principle Zero and E+. van Fraassen's key move is the reminder that the content of empiricism in general, or empiricism $E_{+}$in particular, is not exhausted by $E+$. A crucial further element of both is an admiration for the ideal of empirical science, to wit, the ideal according to which 
all empirical hypotheses deserve an unbiased and open-minded investigation. Empiricists $_{E_{+}}$emulate this ideal when they think of $E+$ as an empirical hypothesis and as subject to rigorous empirical testing (2002: 42-44).

Unfortunately the ideal of an open-minded testing of empirical hypotheses is incompatible with how empiricists $E_{E+}$ intend to rule out metaphysics. Empiricists $E_{E+}$ want $E+$ to immediately and directly rule out of court every alternative $A$ whose $A+$ is incompatible with $E+$. And yet, if $E+$ is an empirical hypothesis, then so are statements contradicting $E+$. Some of the latter are core doctrines $(=A+)$ of alternative philosophical positions, like metaphysics. But if these $A+$ too are empirical hypotheses then they too deserve to be tested in the normal way of empirical science. In other words, these $A+$, or non-Et, cannot be ruled out on the sole the basis that they conflict with $E+$.

For ES all this is reason enough to give up Principle Zero and empiricism $E_{+}$. van

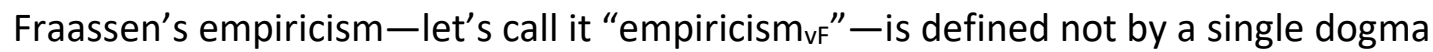
like $E+$ but by a set of VEPPs and beliefs. This gives the admiration for the ideal of empirical-scientific inquiry a new role in the opposition to metaphysics. Empiricism $\mathrm{vF}$ can rule out metaphysics immediately, and without entering into extended debate. This is, van Fraassen claims, because metaphysics does not emulate the conduct of empirical science; it does not value empirical hypotheses; and it does not engage in the empirical testing of philosophical theses. We have here an incompatibility in VEPPs rather than an incompatibility in dogmas. But it still gives the empiricist $t_{\mathrm{vF}}$ a sufficient and immediate reason for rejection or rebellion.

Making VEPPs central to our understanding of empiricism naturally leads to the idea that many philosophical positions are "stances" rather than "dogmas." What characterizes empiricism $\mathrm{VF}$ is a ...

... rejection of explanation demands and dissatisfaction with and disvaluing of explanation by postulate ... calling us back to experience, ... rebellion against theory, ideals of epistemic rationality, ... admiration for science, and the virtue 
they see in an idea of rationality that does not bar disagreement. ... The attitudes that appear in this list are to some extent epistemic and to some extent evaluative, and they may well involve or require certain beliefs for their own coherence. But none are equatable with beliefs. (2002: 47)

As ES has it, empiricism is not the only philosophical position best rendered as a stance. The same applies to materialism. van Fraassen defends this claim by showing that materialists had better not commit to a $M+$ like "Only matter exists." Given the fact that natural science has frequently revolutionized our understanding of matter, "Only matter exists" lacks any determinate content over time. It is much better therefore to understand materialism in terms of VEPPs. For instance, materialists admire the ingenuity of many foundational scientific theories, and they are committed to following science on what there is (2002: 60).

\section{§3. Objectifying Epistemology, Epistemic Voluntarism and Scientific Revolutions}

Having proposed a new understanding of philosophical positions, ES turns to introducing and defending "epistemic voluntarism." Epistemic voluntarism is based on two central claims:

(i) that principles of rationality underdetermine our choice of philosophical stances or scientific paradigms; and

(ii) that a theory of epistemic rationality must not be "objectifying," that is, it must not be a descriptive-explanatory theory of cognition.

By "principles of rationality" van Fraassen means primarily deductive logic, the theory of probability, and the practical syllogism. As long as we stick to these principles we avoid inconsistency and incoherence; we avoid reasoning in ways that-even by our own lights-results in "self-sabotage:" a reasoning that prevents us from reaching our goals $(2002: 88,224)$. 
ES defends (i) by drawing on an idea by William James (1956). According to James, we have two central goals in our epistemic life: to believe as many truths as possible, and to believe as few falsehoods as possible. Since we cannot maximize both goals at once, each one of us implicitly or explicitly fixes their respective "risk-quotients." Each one of us has to choose which of the two goals is more important (either in general or in specific contexts). Deductive logic and the theory of probability do not tell us how to make this choice. Our choice must therefore be based upon VEPPs (2002: 87). Which brings us back to the stances, but with a new twist. Stances now turn out to be important not just as renderings of some philosophical positions; they also turn out to be significant in how we organize our epistemic practices.

$E S$ argues for (ii) by revisiting the issue of scientific revolutions. van Fraassen agrees with Thomas Kuhn's and Paul Feyerabend's thought that, from the perspective of the pre-revolutionary old paradigm, the post-revolutionary new paradigm seems "literally absurd, incoherent, obviously false, or worse-meaningless, unintelligible." And yet, differently from Kuhn or Feyerabend, van Fraassen allows for a different perspective after the revolution. From the post-revolution perspective, the prerevolution viewpoint can be understood as a partial truth (2002: 71). For instance, it follows from Einstein's Special Theory of Relativity that Newton's Laws of Motion are true for entities whose velocity is small when compared with the speed of light (2002: 115) Moreover, van Fraassen thinks that scientific revolutions often result in the discovery of ambiguities in the old paradigm. Thus Newtonians did not realize that mass could be characterized as "proper mass," "gravitational mass," and "inertial mass." And they therefore regarded as absurd the notion that mass varies with velocity (2002: 113).

According to ES, the litmus-test for every epistemology is whether it is able to preserve the rationality of scientific revolutions while acknowledging the element of "conversion" at their very heart. Objectifying epistemologies that describe and explain how our cognitive apparatus fits into the world do not pass muster. They fail the litmus-test since they invariably are enmeshed with the scientific theories of their day. The objectifying epistemology en vogue during the reign of the old 
paradigm licenses the old paradigm's epistemic ways. It therefore cannot but reject as irrational the epistemic practices of the new paradigm (2002: 81).

Epistemic voluntarism does better for three reasons. First, it is prescriptiveevaluative rather than descriptive-explanatory (2002: 82). This lessens the ties to prevalent scientific paradigms. Second, epistemic voluntarism is minimalist (cf. (i) above). And third, epistemic voluntarism gives emotion-or similar "impulses" -a legitimate place in our epistemic life. Points two and three connect epistemic voluntarism to the stance-idea. van Fraassen's thought seems to be that scientific paradigms are, or include, one or more scientific stances.

$E S^{\prime}$ s example for how emotions can change one's epistemic options comes from Franz Kafka's short story Metamorphosis. One morning, Gregor, the son of the Samsa-family, wakes up in the shape of a gigantic beetle, unable to communicate with humans. Initially his parents and his sister Grete think of the beetle as their son or brother. Alas, this rendering of the situation makes their life unbearable. There just is no way to maintain a normal family life when one family member is an insect. It is only when Grete eventually has an emotional breakdown that the parents find a way forward: they take the beetle for nothing but a beetle-and kill it (2002: 106). Grete's emotion enables the family to recognize the situation more correctly, at least when judged retrospectively.

Going beyond van Fraassen's own words, we can use Metamorphosis also to illustrate another central claim of $E S$, to wit, the claim that scientific revolutions involve a re-interpretation of central rules guiding scientific work (2002: Ch. 4). The Samsa-family, throughout the whole episode, operates with the rule Protect the members of your family. Initially this rule is used in a "conservative way:" Gregor and the beetle are taken to be the same person. And thus Gregor-the-beetle remains within the domain of the rule. After Grete's breakdown however, the rule is interpreted in a "revolutionary way:" it is understood as legitimating the killing of the beetle. The family now thinks that the beetle has destroyed and replaced Gregor. Killing the insect safeguards Grete's well-being and revenges Gregor. 
One central rule in empirical science is "Sola experientia!" Defenders of the old paradigm use this rule in a conservative-defensive way. They insist that their paradigm is fully based upon experience (observation and experiment) and free of idle speculation. The proponents of the new paradigm instead accuse the old paradigm of violating Sola experientia!. They use Sola experientia! in a revolutionary way. For instance, Newton's critics identified his assumptions concerning absolute time and space as metaphysical baggage not licensed by experience. The upshot is that scientific revolutionaries do not simply throw scientific rationality overboard. But they interpret it in radically new ways. And there must be an emotion-like "impulse" to set off such developments. (2002: Ch. 4)

\section{§4. Challenges, Allies, Refinements}

In this section I shall discuss three ways of developing van Fraassen's ideas further. These ways will be important when we turn to the issue of relativism in the following sections.

(a) Policies

Several authors have elaborated on what it means to occupy a stance. Paul Teller's $(2004,2011)$ suggestion has rightly received most attention. Teller proposes that committing to a stance is like "adopting a policy." And this involves the following features. (I reformulate them in my own words for the sake of brevity.)

(1) To adopt a policy P is to commit oneself to acting or deciding in accordance with a statement of $P$.

(2) A policy is not true or false, but useful, clever, or easy to use.

(3) Policies can be overridden by other policies.

(4) To apply a policy is to interpret it.

(5) Applying a policy requires "judgment." 
(6) Policies are "expressions or implementations of values" (2004: 167).

(7) Policies simplify decision-making.

(8) It is possible to argue for or against policies. But since policies are at least in part based on value commitments, such arguments cannot be straightforwardly factual. Defences of policies often appeal to more general policies. (2004: 167-168)

One of the strengths of this suggestion is that it sheds light on the relationship between stances and beliefs. Policies are "recipes" for generating beliefs, but not themselves beliefs or belief-like. Note though that policies do not just generate beliefs; policies in turn depend upon beliefs for their operation and defence.

Teller's proposal should not, however, be pushed too far. While stances are plausibly thought of as including policies, it would not be right to equate the two. Stances are more comprehensive than policies; they also include values, emotions, preferences, and beliefs. Starting from the policies we can see how the other elements come into view. Still, the other elements do not simply collapse into parts or moments of policies. Remember that empiricism is about the "rejection of explanation demands ... disvaluing of explanation by postulate ... calling us back to experience, ... rebellion against theory, ideals of epistemic rationality, ... admiration for science, and the virtue they see in an idea of rationality that does not bar disagreement. ..." (2002: 47). It takes some conceptual violence to squeeze all these attitudes and actions into the policy-format.

If we straightforwardly equate stances with policies for generating beliefs, it becomes difficult to appreciate the dichotomy of stance and dogma. If we equate stances with policies we invariably end up wondering whether the stance qua policy isn't simply the road to the dogma (cf. Lipton 2004). Again, we can preserve the difference between the two renderings of philosophical positions only if we allow stances to have content beyond policies. We can then state the differences between the two views of philosophical positions as follows. Principle Zero treats the dogma and its justification as crucial, and everything else (like VEPPs) as merely contingently 
and externally related to the dogma. The stance-account claims that VEPPs are what defines (certain) philosophical positions, and that "dogmas" are typically no more than "glosses" or "post-hoc rationalizations" of non-doxastic elements.

(b) “... not straightforwardly factual ..."

Even though I have cautioned against equating stances and policies, I still find the idea of epistemic policies as parts of stances fruitful. Amongst other things it allows us to get a better handle on epistemic voluntarism. Remember epistemic voluntarism's two central ingredients: it rejects objectifying epistemology, and it involves a minimalism about rationality.

van Fraassen doesn't spend much time searching for potential allies for epistemic voluntarism. But one such potential ally clearly stands out: Hartry Field's 2009 paper "Epistemology without Metaphysics." Already the very title should be music to van Fraassen's ears. Field's meta-epistemology is a form of expressivism; and expressivism has of course been a constant element in empiricist thinking for the past hundred years. As Field has it, a sentence in which we evaluate someone's epistemic justification, "expresses a mental state that is a resultant of norms and factual beliefs" (2009: 252). Put differently, "epistemic evaluations, like other evaluations, aren't straightforwardly factual" (2009:250).

Epistemic norms for Field are not "fairly general normative propositions" (2009: 258); epistemic norms are "policies:" "a policy both for believing (or believing to a certain degree) and for acting so as to improve one's epistemic situation." Epistemic policies may be highly local or general. And they can play a variety of different roles: sometimes we are guided by them; sometimes we evaluate in accordance with them; sometimes we are committed to them. (2009: 260).

It is important to stress that treating epistemic norms as policies is part and parcel of Field's attempt to free epistemology from metaphysics. Epistemic norms are not 
facts in the world, Platonic entities, or "there anyway." They are not truths about epistemic values. They are not true or false at all. van Fraassen would surely agree.

Finally, note that at least in his 2009 paper Field is adamant that his "evaluationism" is a form of "relativism." Every epistemic evaluation is relative to a norm. No sense can be made of an absolute perspective on evaluations or norms. This does not mean that Field would subscribe to the "idea that all norms are equally good" (2009: 255): to attribute this thesis to relativism "is just refusing to take relativism with even an iota of seriousness" (2009: 256). To make epistemic evaluation normrelative is not to say that we cannot evaluate some norms as better than others. It is to say that any such evaluation of norms is in turn relative to norms. As we shall see below, van Fraassen should say pretty much the same thing.

\section{(c) Moderate versus radical epistemic voluntarism}

van Fraassen's epistemic voluntarism is premised on the distinction between stancetranscending principles of rationality on the one hand, and stance-specific values, emotions, preferences and policies on the other hand. One way to put pressure on this distinction is to ask whether epistemic voluntarism isn't demanding too much. van Fraassen himself poses the crucial question thus:

What if I detect a straightforward contradiction in someone's beliefs, conclude that he has sabotaged himself in the management of his opinions, and he turns out to be Graham Priest? Priest happily admits to believing that certain contradictions are or may be true. (2004a: 184)

In response van Fraassen readily admits that Priest's beliefs are consistent. But he goes on to suggest that Priest's logic is "quite different from the one most familiar to us" and that evolutionary arguments might ultimately speak against it (2004a: 185).

This response does not quite seem to address the challenge that Priest poses. The issue is not whether Priest's beliefs about paraconsistent logic are consistent; the 
question is rather whether consistency and coherence should be the supreme touchstones of rationality in the first place. Priest argues that consistency is a matter of degree and must always be weighed against other cognitive values such as "simplicity" ("Is the theory clean and elegant, or is it complex and contrived?"), "unity" ("Does it have to invoke numerous ad hoc hypotheses ...?"), "explanatory power" ("Can the theory be used to explain other things in the same domain ...?") or "parsimony" ("Does the theory multiply entities beyond necessity?") (2005: 123). It is hard to see how evolutionary arguments could work against this account.

If Priest is right about consistency and its relation to other epistemic values, then it becomes difficult for van Fraassen to maintain the distinction between stancetranscending principles of rationality and stance-dependent VEPPs. If consistency can be rationally overruled, then it cannot be the universal and necessary criterion of rationality. If consistency can be overruled, then a stance which does so is not per se irrational. On this alternative picture, differences between rationally acceptable stances may be differences in what weight these stances give different "cognitive values," including the value of consistency.

Of course van Fraassen also has a second stance-transcending criterion of rationality, to wit, the demand not to reason in a way that constitutes self-sabotage. This formal criterion leaves open which principles of rationality and cognitive values one commits to, as long as self-sabotage is avoided. This is a rather vague criterion but perhaps the best we can do.

It should be added that the challenge to van Fraassen's emphasis on consistency does not just come from Priest's controversial views. Philosophers of science like Kuhn, Feyerabend or Peter Lipton (2004) have argued along similar lines. Lipton's position is especially interesting here since he writes in response to van Fraassen's book.

Lipton suggests that Kuhn's paper "Objectivity, Value Judgment, and Theory Choice" (1977) can be read as a "constructive proof of voluntarism." Kuhn offers "shared 
epistemic values" (accuracy, consistency, scope, simplicity, fruitfulness) as the rational backbone of theory- or paradigm-choice. But Kuhn also insists that different scientists may rationally favour some values over other; interpret a given value in differently; or resolve conflicts between these epistemic values in variant ways (Lipton 2004: 153-55). All this is clearly in line with epistemic voluntarism. Note however that consistency is again part of the value-mix and not standing outside as the ultimate touchstone or arbiter.

Lipton raises a number of questions concerning the differences between principles of rationality and (stance-dependent) epistemic policies or values. One question is how much difference is needed for there to be a difference of stance. Do two scientists have different stances just because they weigh the same epistemic value differently? Can we read off a scientist's inferences which stances, values or policies they have adopted? Lipton is sceptical since very often there will be other possible explanations like background beliefs or differences in evidence (2004: 155-157).

Lipton has a point. Perhaps the best way to respond to his challenge is to modify van Fraassen's bifurcation of principles of rationality and stance-dependent values and policies. The modification I have in mind is to follow Kuhn and Priest and let rationality consist in one's honouring all or some of the epistemic values. Kuhn and Priest list some of these values, but no doubt there are more. Indeed, which epistemic values there are, can only be determined by research in cognitive psychology and the history and philosophy of science (including epistemology). This does not give us a firm and fixed base; but perhaps it is the conditio humana to cope without such foundation.

To sum up this train of thought, we should distinguish between moderate and radical voluntarism. van Fraassen's voluntarism is moderate in so far as he assumes a clear-cut borderline between stance-transcending principles of rationality and stance-dependent VEPPs. Radical voluntarism denies that there is a clear borderline here. ${ }^{i}$ 


\section{§5. Relativism}

In this section I shall discuss the relationship between epistemic voluntarism (including the stance-idea) and epistemic relativism from two different angles. In subsection (a) I shall focus on the question whether epistemic voluntarism involves a form of relativism. In (b) I shall suggest that at least some forms of relativism can fruitfully be rendered as stances rather than doctrines. In (c) I shall deal with some general objections regarding my argument in (b).

(a) Epistemic voluntarism and relativism

Epistemic voluntarism even in its moderate form seems to involve a form of epistemic relativism:

(I) The epistemic status of judgements is relative to stances.

(II) Different stances evaluate the same judgements differently.

(III) There is no perspective from which stances can be neutrally and absolutely ranked.

(IV) The move from one stance to another can have the character of a "conversion:" principles of rationality combined with empirical data cannot compel a transition from one stance to another.

van Fraassen himself invokes the idea of conversion as follows:

Being or becoming an empiricist will then be similar or analogous to conversion to a cause, a religion, an ideology, to capitalism or to socialism, to a worldview such as Dawkins's selfish gene view or the view Russell expressed in "Why I am Not a Christian." (2002: 60)

And elsewhere he comments: 
If this is relativism, it is certainly not debilitating relativism - it is only an acknowledgement of the logic of this aspect of the human condition (2004b: 11).

I take it that by "debilitating relativism" van Fraassen means a form of relativism that makes its advocate unable to judge or argue. Perhaps he is thinking of versions of epistemic relativism that declare all stances to be "equally valid." Clearly, if all stances are equally valid then there cannot be much point in arguing whether the beliefs licenced by one stance are superior to those licensed by another stance.

van Fraassen's alternative is worth spelling out pedantically. I shall here assume moderate rather than radical epistemic voluntarism. Let "S1" and "S2" stand for two incompatible stances (or paradigms), "As1" and "Bs1" for two proponents of S1; "C $\mathrm{Cs}_{\mathbf{s}}$ " for a proponent of $\mathrm{S} 2$, and " $p$ " for a proposition over which $A, B$, or C disagree.

Clearly, when $A_{s 1}$ and $B_{s 1}$ disagree over $p$, they have a rich shared background of principles of rationality and stance-specific VEPPs to adjudicate their differences. This shared background will often determine which view on $p$ is bindingly correct and which is incorrect.

Could $A_{s 1}$ convince $C_{s 2}$ to stop occupying S2? One possibility is that adherence to S2 is irrational in light of the stance-transcending principles of rationality, and that $C_{s 2}$ therefore engages in self-sabotage. Here the principles of rationality are a common and neutral ground.

The situation is different when neither side flouts the principles of rationality. This does not pre-empt argument and changing the other's mind, but there no longer is a universal common ground capable of adjudicating the differences. At least two things might happen in such setting: 
- As1 might be able to show $C_{s 2}$ that one of $C_{s 2}$ 's VEPPs or beliefs is insufficiently motivated by a VEPP or belief that $A_{\mathbf{s} 1}$ and $C_{\mathbf{S 2}}$ share (but that is not necessarily shared by other stances).

- As1 might be able to show $C_{s 2}$ that one of $C_{s 2}$ 's VEPPs or beliefs is insufficiently motivated by one of $\mathrm{C}_{\mathbf{s} 2}$ own beliefs or VEPPs (not shared by $\mathrm{Ass}_{\mathbf{1}}$ ).

What should $A_{\mathbf{s} 1}$ say about $C_{\mathbf{S 2}}$ or $\mathbf{S 2}$ more generally, when neither of these strategies succeed? One thing is clear: As1 is not compelled to treat his own S1 and C's S2 as "equally valid." Given As1's VEPPs and beliefs, there may well be good grounds for As1 to reject S2 and at least some of the VEPPs and beliefs that constitute S2.

The above reflections were based on moderate epistemic voluntarism. The situation changes when we replace moderate with radical epistemic voluntarism. In this case the common ground will be smaller. Instead of stance-transcending principles of rationality we only have a partially shared set of epistemic values given different weights. But even in this case, argument is surely possible-at least when the values relevant to the adjudication between S1 and S2 are shared.

Where does all this leave the debate between empiricists ${ }_{\mathrm{vF}}$ and metaphysicians? Assume that both sides honour the principles of rationality and thus have coherent systems of beliefs and values. Would empiricists $\mathrm{SF}_{\mathrm{VF}}$ be able to reject metaphysics under these conditions? van Fraassen's answer should be clear. Empiricists recognize that they share VEPPs and beliefs with sensible metaphysicians (an admiration for aspects of science, for example). But it does not follow that empiricists have to tolerate the metaphysical stance as an equal. To repeat, another stance does not become my stance's equal just because the other stance is consistent and coherent. The empiricists $\mathrm{VF}^{\prime}$ values - and especially the value attached to the empirical-scientific testing of empirical hypothesis-license a direct rejection of metaphysics. ${ }^{\text {ii }}$ Still, this does not preclude empiricists ${ }_{\mathrm{vF}}{ }^{\prime}$ efforts at convincing the metaphysicians-albeit that there is no guarantee of success. 
To summarize what I take to be the main lesson of this subsection, I hope to have made plausible that van Fraassen's epistemic voluntarism does indeed involve a form of relativism. But this relativism is benign rather than debilitating: it does not declare all stances equally valid, and it allows for meaningful discussion across stances.

(b) Applying the stance-idea to relativism: The example of SSK

In this subsection I shall change tack. Rather than exploring the link between voluntarism and relativism, I shall here concentrate on the stance-idea in its relationship to relativism. My guiding question is this: Is (epistemic) relativism a philosophical stance (like empiricism $\mathrm{vF}_{\mathrm{VF}}$ ? Or, more precisely, are all forms of relativism best thought of as stances, or perhaps only some? These are intriguing questions suggested by van Fraassen's work. Addressing them adequately would demand a separate paper. Here I am content to give one example of a form of relativism that is naturally thought of as a stance. It is also a position that is similar to van Fraassen's in some unexpected ways. I am referring to the "Sociology of Scientific Knowledge" (=SSK), as it has been developed and defended by David Bloor. Like empiricism $\mathrm{vF}$ So also SSK is naturally thought of as a "rebellion." But in Bloor's case the rebellion is not just against metaphysics, it is against philosophy tout court: "To ask questions of the sort which philosophers address to themselves is usually to paralyze the mind" (1991: 52). In particular Bloor dismisses work in epistemology and the philosophy of science. He faults these fields for having no "controlled input of data." Since such control is missing, epistemological discussions are "simply affirmations of the values and perspectives of some social group" (1991: 80). Bloor tries to substantiate this allegation by showing that Popper's and Kuhn's philosophies of science are expressions of values and "thought-styles" going back to Enlightenment (Popper) or Romantic (Kuhn) ideologies (1991: 62).

Bloor does not just compare philosophy unfavourably to science. He also finds philosophy deserving of less respect than theology. This has to do with the arguments over relativism versus absolutism. In the Vatican Bloor finds "a clear- 
sighted absolutism in action." For instance, Pope Benedict XVI's argument "against relativism is grounded in his faith in God as the ultimate source of truth" (2007: 254). Secular philosophers mistakenly think that they can defend absolutism without explaining their access to absolute truth.

Despite his contempt for much of philosophy, Bloor is happy to declare his allegiance to certain philosophical "isms." He sides with empiricism if it is understood as a "psychological theory" urging that "our perceptions influence our thinking more than our thinking influences our perceptions" (1991: 33). He accepts materialism if it amounts to seeing humans as "part of the material world" and as holding that "social learning is part of how the material world functions" (1991: 34). And he commits to naturalism as the view that "knowledge and belief ... must be grounded in the natural world, and they are themselves things which are susceptible to scientific explanation" (2007: 252). None of these commitments are defended in any detail; they are seen as preferences underpinning SSK.

van Fraassen locates the main difference between the empiricist and the materialist stances in their respective admiration for empirical science. Bloor also seeks to follow the model of natural science:

I have taken for granted and endorsed what I think is the standpoint of most contemporary science. In the main, science is causal, theoretical, value-neutral, often reductionist, to an extent empiricist, and ultimately materialistic like common sense. (1991: 157)

Bloor's well-known "strong programme" is said to "embody the same values which are taken for granted in other scientific disciplines." The strong programme recommends that investigations in SSK be "causal," "impartial," "symmetrical" and "reflexive" (1991: 7). This is of course to advocate a set of policies for research rather than a theory about the world.

Bloor elsewhere presents SSK as part of the "Einheitswissenschaft" of logical positivists. He draws particularly on the physicist Philipp Frank and his book 
Wahrheit: Relativ oder Absolut (1952) (Bloor 2011). Frank argues that the progress of science "has been accompanied by an increase in 'relativisation.' Ever more concepts are modified with the expression 'relative to a given frame of reference'" (1952: 73). Moreover Frank recommends relativism as "the only effective weapon against any kind of totalitarianism" (1952: 14). Again, the value-orientation is palpable.

When it comes to motivating and defending relativism, Bloor has three lines of argument. One is to say that relativism is simply the denial of absolutism: "no absolute knowledge and no absolute morality": "Knowledge and morality cannot transcend the machinery of our brains and the deliverances of our sense organs, the culture we occupy and the traditions on which we depend" (2007: 251). According to the second line of argument, SSK-relativism is supported by the fact that many impressive empirical studies rely on it as a methodological guide (Barnes and Bloor 1982: 25). The third line of argument seeks to show that philosophical critics conflate SSK-relativism with unsavoury doctrines like "subjectivism," "irrationalism," or "scepticism" (Bloor 2011: 433).

Finally, Bloor's theory of rationality is at least structurally similar to the epistemic voluntarism defended by van Fraassen. Recall that van Fraassen restricts principles of rationality to deductive logic and the theory of probability, or-alternatively-to principles that prevent us from falling into self-sabotage. Over and above these principles we are free to choose. Bloor's dichotomy is different. For him the basic level consists of our "natural inductive" or "natural deductive propensities." These are studied by cognitive science, and are taken to be common to normal members of the human species. The second level consists of systems of "normative" rationality; these are different codifications of our reasoning propensities, according to the interests and negotiations of different groups. Normative rationality is the subject matter of the sociologist. (1991: 168-9)

Since normative rationality is thus invariably a local phenomenon, Bloor thinks it is unlikely that the debate between relativism and absolutism could ever be resolved: "No relativist should believe that relativism can be proven true or that history is on its side ..." (2011: 450) "So the sociology of knowledge is not bound to eliminate the 
rival standpoint. It only has to separate itself from it, reject it, and make sure that its own house is in logical order." (1991: 12)

\section{(c) Dealing with an objection}

There clearly are costs in reconstructing Bloor's relativism as a stance rather than as a doctrine. It makes it more difficult to argue for or against it. Rather than testing the consistency of a brief dogma, and its coherence with other independently established truths, we have to engage with VEPPs that do not have truth-values at all. That makes the task of the critic a lot harder.

There is also a deeper issue here. The obvious objection to the whole stance-idea might be put as follows: Of course, in his writings Bloor appeals to all sorts of VEPPs, and obviously he suggests a range of SSK policies. No-one denies that this is so. But why should we make these VEPPs part and parcel of his relativism? Why can't we distinguish between his relativistic credo or dogma-say, "there are no context-free or super-cultural norms of rationality" (Barnes and Bloor 1982: 27) - on the one hand, and the various motivations for this credo, and the consequences drawn from it, on the other hand?

The right answer seems to me to be the following. To attribute relativism as a stance is to make a claim about where one should locate the core or essence of the respective position. Do the advocates of the position foreground a claim or doctrine (about the world), and do they marshal their evidence and VEPPs as arguments for this doctrine? Or do the advocates put the emphasis on rebellion, admiration, and VEPPs, and treat stated credos as no more than rough glosses intended to point beyond themselves at the underlying epistemic and evaluative commitments?

In Bloor's case we are clearly dealing with the latter scenario. The claim that "there are no context-free or super-cultural norms of rationality" is not simply a descriptive claim for which Bloor assembles evidence. It is also, and indeed primarily, a reference first to his rebellion against any kind of absolutes, and second to his commitment to leave the study of human rationality to the empirical sciences. 
Rationality is to be studied empirically, and to do so is to identify contextual dependencies (albeit that the relevant context might sometimes be that of the whole species).

To see Bloor's position as a "stance" might also help us understand why arguments between philosophers and SSK-advocates are so often fruitless. Philosophers are focused on doctrines that they can test for consistency and coherence. And they get palpably annoyed when they do not find such snappy position statements. Philosophers see the lack of such statements as a lack of conceptual clarity and intellectual commitment. Indeed, confronted with this situation philosophers sometimes use something like the stance-idea-but with strictly negative connotations: the SSK-advocate is seen as guided by an animus against science, by physics- or philosophy-envy, and by a rejection of the demands of intellectual responsibility (Haack 1998). This might convince fellow philosophers, but it leaves sociologists cold.

One of van Fraassen's central motivations for interpreting empiricism as a stance, is the desire to find a common denominator for the numerous self-proclaimed empiricists in our tradition, from the Ancient Greek school of physicians, the "Empirici," to the Vienna Circle and beyond. A short E+ like "Experience is the one and only source of information" (2002: 43) doesn't do the trick. Invoking the rebellion against metaphysics (and related VEPPs) works much better. I submit that the same is true for relativism. If we start from a brief three-point definition, say of the kind offered in Paul Boghossian's influential Fear of Knowledge (2006: 73), it is difficult to find any self-proclaimed, or otherwise identified, relativists who actually commit to this " $R+$ ". iii Boghossian claims to be targeting Richard Rorty in particular, but he never shows in any detail that Rorty would accept Boghossian's definition of epistemic relativism (2006: 60-63). The situation would be no different if instead we used the definition of relativism given in $\S 5(a)$ above.

Perhaps as is the case with empiricism, so also in the case of relativism it is easier to find a common denominator if we turn from dogmas to stances. What unites authors accused of, or happily embracing, forms of relativism - from the sophists to 
Bloor and Rorty-is first and foremost the rebellion against forms of metaphysics, epistemology or ethics that posit absolutes (Herbert 2001; Kusch 1995, Kusch et al. 2019). These absolutes are variously taken to be divine commands, ultimate scientific truths, consensi gentium, apodictic intuitions, or "truths that are there anyway." Different relativist authors are preoccupied with opposing different such absolutes. But they all share the same animus. Interestingly enough, this rebellion against absolutes situates many relativists in the proximity of empiricism: the opposition to metaphysics is obviously a commonality. Many relativists also share further values or virtues: they oppose individualism, intellectual imperialism, or unchecked epistemic hierarchies, and they value epistemic humility, tolerance or equality. It seems to me that the shift from a relativist dogma to a relativist stance might bring into view a "tradition of relativist thinking" that up to now has been largely invisible.

\section{§6. Stance Relativism and Boghossian's Challenges}

In this final section I shall discuss how stance-relativism of the kind discussed in this paper fares against Boghossian's battery of anti-relativist arguments.

(1) By "absolute relativism" Boghossian means a form of relativism that works with a mixture of absolute and relative principles. The paradigmatic case of this view is a relativism of manners based on the one absolute principle: "When in Rome do as the Romans do." Or think of subjective Bayesians for whom the Bayesian formula is the one and only absolute principle. (Boghossian 2011: 67)

Boghossian rejects absolute relativism as a viable form of relativism. By accepting the existence of one absolute principle, Boghossian submits, the relativist has lost what surely must be her strongest card, to wit, worries how absolute principles fit into the empirical world, and how they can be known by finite and fallible creatures. Moreover, the absolute relativist has no good answer to the question why there could not in principle be more than one absolute norm. (Boghossian 2011: 68) 
A voluntaristic-epistemic relativism (of stances) can easily appear to be an instance of "absolute relativism." After all, van Fraassen treats principles forbidding inconsistency and incoherence as definitive of rationality, and a different from epistemic policies. Nevertheless, it seems possible to defend van Fraassen against Boghossian's considerations.

One line of defence is to shift from moderate to radical epistemic voluntarism. This is the shift from fixed stance-transcending principles of rationality to stance-relative selections from a larger set of epistemic values. None of these values is absolute in the sense that it has to be present in every stance, or that it has to be always interpreted in the same way. Indeed, the set itself could be seen as a contingent product of our evolutionary and social history.

Boghossian might regroup and focus instead on the demand not to self-sabotage. Is this not a universal demand of rationality? And doesn't its presence make epistemic voluntarism a case of absolute relativism after all? Here too the epistemic voluntarist has a response-at least if she borrows a line from Bloor. She might insist that seeking to avoid self-sabotage is simply something we (most of us, most of the time) instinctively do. It is not a principle of rationality that "is there anyway," but part and parcel of the "natural rationality" installed in us by a contingent evolutionary history.

(2) Boghossian readily acknowledges that our epistemic practices vary, but he denies that that this variation supports relativism. What variation there is can be explained by the fact that our absolute rules are sometimes vague and unspecific. They leave room for choice. (Boghossian, pers. comm.; 2006: 110). This suggestion seems to fit with van Fraassen's moderate epistemic voluntarism with its principles of rationality that leave our choices of stances or paradigms underdetermined. This underdetermination is removed only once VEPPs do their work.

The first thing to note here is that Boghossian's idea does not in fact block relativism. If true, all it suggests is that the scope of relativism is not unlimited. But the breadth of the scope remains completely open. Clearly, Boghossian, van Fraassen and Bloor 
are likely to have very different views on this breadth. Moreover, the move from moderate to radical epistemic voluntarism again avoids Boghossian's rendering of the relativist position. The radical version of epistemic voluntarism does not fit into Boghossian's template.

And yet, Boghossian might have a further reply specifically addressing radical epistemic voluntarism: If we allow, as we should, for appropriate forms of idealization and abstraction, then surely we will be able to construct general and absolute epistemic principles to which every normal human being is at least implicitly committed.

The radical epistemic voluntarist might reply as follows. Yes indeed, we might proceed in the way Boghossian suggests. But we should not expect this methodology to lead to one unique outcome. On the contrary, work done in this way is faced with all the old issues concerning the underdetermination of theory by observation. Moreover, it might well be highly artificial and contrived to bring all of our epistemic folkways under one small set of absolute epistemic principles. Not to forget that abstract principles might be far too schematic to guide our epistemic conduct. Boghossian's method would thus produce a merely schematic, but ultimately hollow form of absolutism. iv And last, but not least, what should we do with the actors' own perspective on their epistemic folkways? Should we simply ignore this perspective? If not, what then should we say when the actors do not recognize their own reasoning in the epistemologists' reconstructions and idealizations? (Kinzel and Kusch 2018)

(3) Stances and perhaps even paradigms can be more or less different, more or less distant, from one another. The greater the difference or distance, the more we need the idea of "conversion" for capturing what happens when the folk or scientists shift from one stance or paradigm to another. And it is only when conversion is needed for capturing the change that epistemic relativism is vindicated. 
Parts of Boghossian's 2006 book can be read as offering a suggestion for how the relativism-motivating distance or difference between stances or paradigms can be captured. Boghossian distinguishes between "fundamental" and "derived" "epistemic principles." A fundamental principle concerning observation licences perceptual beliefs under certain general conditions. A derived principle concerning observation licences the perceptual beliefs of a specific person, or perceptual belief given a specific instrument (like a microscope or telescope). Boghossian claims that two "epistemic systems" - that is, two systems of epistemic principles - are "fundamentally different" when they differ in at least one fundamental epistemic principle. And fundamental difference of epistemic systems is what defines a relativistic setting. Of course, Boghossian's interest in all this is to bury relativism, not to praise it. He therefore goes on to argue that relativists have so far failed to offer a single convincing case of such fundamental difference between epistemic systems. In particular, Galileo and Cardinal Bellarmine did not differ over any fundamental epistemic principle. (Boghossian 2006: 63-69, 90-91, 103-105)

Can Boghossian's concepts and criticisms be applied to van Fraassen's relativism of stances? Has van Fraassen offered convincing examples of differences in fundamental epistemic principles? To my mind stance-relativism is not threatened by Boghossian's considerations. To begin with, it is unlikely that van Fraassen's would accept Boghossian's criterion for a relativism-inducing difference in stances, that is, a difference in at least one fundamental principle. van Fraassen's perspective is coherentist rather than foundationalist. What distinguishes Cardinal Bellarmine from Galileo is not one fundamental epistemic principle but a whole host of beliefs and VEPPs. It is the number and weight of these differences that requires a conversion, not the fundamental character of one of them. The distance from Boghossian increases further as we shift from moderate to radical epistemic voluntarism: the latter does not accept that everyone must share (the interpretation of) the same basic epistemic values.

(4) As Boghossian has it, the epistemic relativist's single best argument against absolute epistemic principles goes as follows: 
(\#) To justify our belief that our epistemic system $S$ is absolutely correct, we invariably have to rely on this very $S$. This procedure is circular and thus unacceptable. Hence we cannot justify our belief that $S$ is absolutely correct. And the same is true of any other $S$.

Boghossian rejects (\#). It is not generally true that no epistemic principle $P$ can be used to justify itself. Such circularity is forbidden only if $P$ has already become independently doubtful. (2006: 96-102)

What would or could van Fraassen respond? Is he committed to rejecting epistemic circularity? I think not. By which I do not mean to suggest that van Fraassen agrees with Boghossian that the relativist has no good argument for his opposition to epistemic absolutes. As we saw above, van Fraassen holds that the best evidence for epistemic voluntarism, and thus for relativism, comes from the history of scientific revolutions. He is convinced that there have been many instances where the progress of science has involved seismic shifts in our epistemic values and policies. It is scientific revolutions, not any apriori reflections on rule-circularity, that should push us in the direction of relativism.

(5) Boghossian (2011: 60-66) finds epistemic relativism inherently unstable. On the one hand, the relativist allows that epistemic systems fundamentally different from her own are, in some sense, as valid as her own. On the other hand, the relativist also prefers her own epistemic system and does not give it up. How can these two attitudes be reconciled? Boghossian is doubtful that relativism can deliver a plausible solution.

van Fraassen's response is perhaps best captured in the following remark (which was not addressing Boghossian's considerations): 
I remain convinced that genuine, conscious reflection on alternative beliefs, orientations, values - in an open and undogmatic spirit-does not automatically undermine one's own commitments. (2011: 156)

Of course, we need an argument defending this conviction. I shall use radical epistemic voluntarism for providing such argument. It might go as follows. Under certain conditions, we can-from the perspective of our stance-recognize the VEPPs and beliefs of another stance as justifiable. That is, we can come to see the VEPPs and beliefs of another stance as rational provided only that we can identify a way of justifying them with reference to some plausible combination and weighting of epistemic values. If this proves possible, then the other stance is in some sense "equal" to our own. And yet, the fact that we can see the other stance in this light does not give us a reason to convert to it. After all, we might well have VEPPs and beliefs that differ from those of the other stance. And our VEPPs and beliefs might give us sufficient reason not to convert.

The situation is different when we are faced with a crisis of confidence in our own epistemic system, when we are involved in a scientific (or other) revolution (of thought). In such situation we do not regard the other paradigm (or stance) as equal to our own; we regard the alternative as absurd. And we no longer know how to go on with our own paradigm. Note however that this is not the situation of relativistic epistemic voluntarism. The advocates of the latter do not (as yet) have any cause for a crisis of confidence (though they might well think of the absolutist alternatives as absurd).

\section{§7. Conclusion}

In this paper I have tried to develop van Fraassen's epistemic voluntarism concerning stances and scientific paradigms in two main ways: by distinguishing between moderate and radical forms of epistemic voluntarism, and by rendering all forms of epistemic voluntarism as so many forms of epistemic relativism. In the process I have suggested that epistemic relativism can sometimes take the form of a stance rather 
than a dogma, and that a relativistic epistemic voluntarism can be defended against Boghossian's well-known battery of arguments against epistemic relativism. I hope to have made plausible the general thought that the two key ideas of van Fraassen's Empirical Stance are worthy of further reflection and refinement. ${ }^{v}$

\section{Literature}

Barnes, B. and D. Bloor (1982), "Relativism, Rationalism, and the Sociology of Knowledge," in M. Hollis and S. Lukes (eds.), Rationality and Relativism, Oxford: Blackwell, 21-47.

Bloor, D. (1991), Knowledge and Social Imagery, $2^{\text {nd }}$ ed., Chicago, Ill.: Chicago University Press.

Bloor, D. (2007), “Epistemic Grace: Antirealism as Theology in Disguise," Common Knowledge 13: 250-280.

Bloor, D. (2011), "Relativism and the Sociology of Knowledge," in Hales 2011: 433-456.

Boghossian, P. (2006), Fear of Knowledge: Against Relativism and Constructivism, Oxford: Clarendon.

Boghossian, P. (2011), “Three Kinds of Relativism," in Hales 2011: 53-69.

Field, H. (2009), "Epistemology without Metaphysics," Philosophical Studies 143: 249-290.

Frank, P. (1952), Wahrheit: Relativ oder Absolut? Zürich: Pan-Verlag.

Haack, S. (1998), Confessions of a Passionate Moderate, Chicago: University of Chicago Press. 
Hales, S. (2011), A Companion to Relativism, Oxford: Wiley-Blackwell.

Herbert, C. (2001), Victorian Relativity: Radical Thought and Scientific Discovery, Chicago: University of Chicago Press.

James, W. (1956), "The Will to Believe," in W. James, The Will to Believe and Human Immortality, New York: Dover Publications, pp. 1-31.

Kinzel, K. and M. Kusch (2018), “De-Idealizing Disagreement, Rethinking Relativism," International Journal of Philosophical Studies 26: 40-71.

Kuhn, T. S. (1977), “Objectivity, Value Judgment, and Theory Choice,” in T. S. Kuhn, The Essential Tension Chicago: The University of Chicago Press, pp. 320-339.

Kusch, M. (1995), Psychologism, London: Routledge.

Kusch, M., K. Kinzel, J. Steizinger, N. Wildschut (eds.) (2019), The Emergence of Relativism, London: Routledge.

Lipton, P. (2004), “Epistemic Options,” Philosophical Studies 121: 147-158.

Priest, G. (2005), Doubt Truth to be a Liar, Oxford and New York: Oxford University Press.

Teller, P. (2004), Review of The Empirical Stance by B. C. van Fraassen, Philosophical Studies 121: 159-170.

Teller, P. (2011), "Learning to Live with Voluntarism," Synthese 178: 4966.

van Fraassen, B. (2002), The Empirical Stance, Princeton: Princeton University Press. 
van Fraassen, B. (2004a), “Replies," Philosophical Studies 121: 171-192.

van Fraassen, B. (2004b), "Reply to Chakravartty, Jauernig, and McMullin," unpublished typescript. Accessed last on September $13^{\text {th }}, 2018$, from http://www.princeton.edu/ fraassen/abstract/ReplyAPA-04.pdf

van Fraassen, B. (2011), “On Stance and Rationality," Synthese 178: 155-169.

\footnotetext{
' In correspondence van Fraassen has suggested that his acceptance of Carnap's "Principle of Tolerance" for languages is a radical-epistemic-voluntarist element in this work. Nevertheless, van Fraassen is not convinced that "consistency is just one epistemic virtue among others." He argues as follows. Arthur Prior's "tonk-language" is an instance of a language in which every sentence is inconsistent. The relevant sense of inconsistency here is proof-theoretic: everything follows logically from any sentence or set of sentences. In such language all distinctions collapse. van Fraassen concludes: "... a position within which all distinctions collapse could not even be called 'relativist'." -- I agree with the view that relativism is not the same as mysticism. The latter typically involves the idea of a "coincidentia oppositorum", as Nicholas of Cusa put it. (I have heard Priest explain similar ideas from Buddhism.) To be clear, I do not adhere to these views. But are they irrational by definition? I am not so sure. Moreover, I do not think that the radical voluntarist must regard "consistency as just one epistemic virtue among others". The "among others" perhaps hides an ambiguity. It is easily heard as "no better or no worse, and no more important" than the others. But in the present context it could also mean "it is part of the set of epistemic virtues and can sometimes be restricted in its scope and outweighed by other virtues". I would tie radical voluntarism to the second rendering, not to the first.

ii Of course determined metaphysician will resist this argument. They will insist that it is the very subject matter of metaphysics that precludes the option of empirical testing. Clearly, this topic requires much more space than I have here. I am grateful to Delia Belleri for pushing me on this point.

iii Of course in some cases this will be so because the relativists adopt doctrines that are much more sophisticated than Boghossian allows for. This would make Boghossian's arguments instances of the straw-man fallacy.

iv Here I am indebted once more to Delia Belleri.

${ }^{\vee}$ Work on this paper was made possible by ERC Ad Grant \#339382. For comments I am deeply indebted to Bas van Fraassen, Delia Belleri, Anne-Kathrin Koch, Sophie Veigl, Dominik Finkelde and Paul Livingston.
} 